\title{
ANALISIS BIAYA SATUAN METODE ACTIVITY BASED COSTING (ABC) DALAM EVALUASI TARIF PELAYANAN DI KLINIK SPESIALIS BEDAH SARAF RUMAH SAKIT “ $X$ " SURABAYA
}

\author{
Dinda Rahmaniar*, Thinni Nurul Rochmah* \\ *Fakultas Kesehatan Masyarakat, Universitas Airlangga, Surabaya \\ Email: dinda.rahmaniar@gmail.com
}

\begin{abstract}
ABSTRAK
Perkembangan organisasi rumah sakit menuntut diselenggarakannya manajemen keuangan yang efektif dan efisien termasuk dalam hal penetapan tarif. Penetapan tarif rumah sakit dapat mempengaruhi profitabilitas dan brand image rumah sakit. Rata-rata profit margin RS "x" Surabaya dari tahun 2013 sampai dengan tahun 2015 adalah (-4,02\%). Penelitian ini dilakukan untuk menganalisis biaya satuan dalam evaluasi tarif pelayanan di RS "X" Surabaya. Penelitian ini dilaksanakan dengan studi cross sectional menggunakan pendekatan kuantitatif serta pengumpulan data melalui observasi dan wawancara mendalam. Kalkulasi biaya dilakukan melalui analisis biaya dengan metode Activity Based Costing (ABC) pada klinik spesialis bedah saraf di RS "X" Surabaya. Berdasarkan hasil penelitian didapatkan 9 produk pelayanan di klinik spesialis bedah saraf dan memiliki 2 tarif pelayanan yang rasional, 5 tarif rasional biaya langsung, dan 2 tarif lainnya adalah tarif tidak rasional. Kesimpulan yang dapat ditarik adalah tarif produk pelayanan klinik spesialis bedah saraf di RS "X" Surabaya cenderung pada tarif rasional dengan biaya langsung. Hal tersebut dapat disebabkan oleh output pelayanan kecil, waktu aktivitas besar, biaya tidak langsung besar, dan jumlah cost driver yang besar. RS " $\mathrm{X}$ " Surabaya dapat melakukan efisiensi biaya pada bagian administrasi dan manajemen serta bagian IPS. Hasil unit cost dapat dijadikan dasar dalam proses standarisasi pelayanan, evaluasi, dan penentuan tarif menggunakan strategi cost based pricing sebagai upaya penerapan activity based management di rumah sakit.
\end{abstract}

Kata Kunci : Activity-Based Costing, Analisis Biaya, Tarif, Unit Cost

ABSTRACT

The development of the hospital organizations is demanding the convening of effective and efficient financial management, including in terms of tariff setting. Hospital tariff can affect profitability and brand image. The average profit margin of " $X$ " Hospital Surabaya from 2013 until 2015 was (-4.02\%). This study was conducted to analyze the unit cost in the evaluation of tariff in the " $X$ " Hospital Surabaya. This is descriptive research with cross sectional study using a quantitative approach in which the data were collected by observation and in-depth interviews. The calculation of costs was carried out through analysis by Activity Based Costing (ABC) method in the nerve surgical special clinic in the " $X$ " Hospital Surabaya. The results of the research showed that nerve surgical special clinic with a total of 9 service products have 2 rational tariffs, 5 rational tariffs of direct costs, and 2 was the irrational tariffs. The conclusion of this research is most of tariffs of service products in nerve surgical special clinic are rational tariffs of direct cost. This can be caused 
by a small service output, a long time activity, large indirect costs, and a large number of cost drivers. The " $X$ " Hospital Surabaya can makes the cost efficiency in the administration management and IPS unit. The results of unit cost can be used in the process of service standardization, evaluating, and determining tariffs using cost-based pricing strategy as an effort to implement activity-based management in the hospital.

Keywords : Activity-Based Costing, Cost Analysis, Tariff, Unit Cost

\section{PENDAHULUAN}

Rumah sakit adalah institusi pelayanan kesehatan yang menyelenggarakan pelayanan kesehatan perorangan secara paripurna dengan menyediakan pelayanan rawat inap, rawat jalan, dan gawat darurat (UU No. 44 Tahun 2009). RS " $X$ " Surabaya merupakan rumah sakit swasta tipe B yang melakukan penetapan tarif menggunakan sistem penetapan biaya secara tradisional dengan strategi competitor based pricing pada rumah sakit lain. Penetapan tarif yang hanya didasarkan pada perbandingan tarif dengan rumah sakit lain menimbulkan ketidakakuratan dalam pembebanan biaya pelayanan kesehatan.

Rumah sakit sebagai organisasi kesehatan tidak hanya bertujuan menjalankan misi sosial dan kemanusiaan (social orientetd) tetapi juga bertujuan mencari keuntungan (profit oriented) untuk meningkatkan kualitas pelayanan kesehatan dan atau meningkatkan kesejahteraan sumber daya manusia didalamnya (Mininjaya, 2004). Perkembangan organisasi rumah sakit menuntut diselenggarakannya manajemen keuangan yang efektif dan efisien termasuk dalam hal penetapan tarif. Penetapan tarif rumah sakit dapat mempengaruhi profitabilitas dan brand image rumah sakit.

$$
\text { Berdasarkan Keputusan Menteri }
$$

$\begin{array}{lll}\text { Kesehatan } & \text { RI } & \text { Nomor }\end{array}$
560/MENKES/SK/IV/2003 tentang Pola Tarif Perjan Rumah Sakit pada pasal 3 menjelaskan bahwa dalam menentukan besaran tarif pelayanan rumah sakit diperhitungkan atas dasar unit cost dari setiap jenis pelayanan dan kelas perawatan, yang perhitungannya memperhatikan kemampuan ekonomi masyarakat, standar biaya atau bench marking dari rumah sakit yang tidak komersil yang ditetapkan oleh Direksi setelah mendapat persetujuan dari Dewan Pengawas.

RS "X" Surabaya merupakan rumah sakit yang masih dalam tahap berkembang dan berupaya untuk meningkatkan kualitas pelayanan yang juga tidak terlepas dari upaya pencapaian target profit rumah sakit. Berikut adalah data profit margin RS " $X$ " Surabaya tahun 2013 hingga tahun 2015 : 
Tabel 1. Profit Margin RS "X” Surabaya Tahun 2013-2015.

\begin{tabular}{|c|c|}
\hline Tahun & Profit Margin \\
\hline 2013 & $-8 \%$ \\
\hline 2014 & $-2 \%$ \\
\hline 2015 & $-2 \%$ \\
\hline Rata-rat & t margin $\quad-4,02 \%$ \\
\hline
\end{tabular}

Berdasarkan uraian di atas masalah yang diangkat adalah besarnya profit margin negatif pada tahun 2013 sampai dengan 2015 di RS “X” Surabaya dengan rata-rata profit margin $(-4,02 \%)$ sehingga memicu defisit anggaran. Oleh karena itu tujuan dalam penelitian ini adalah melakukan analisis biaya satuan metode Activity Based Costing (ABC) dalam evaluasi tarif pelayanan di klinik spesialis bedah saraf RS “X” Surabaya.

\section{METODE}

Penelitian ini merupakan penelitian kuantitatif dengan desain penelitian deskriptif. Berdasarkan jenis penelitiannya, maka penelitian ini termasuk penelitian observasional karena peneliti tidak melakukan perlakuan kepada subjek penelitian hanya melakukan pencarian informasi dan pendataan. Berdasarkan Tabel 2 Facility Activity dan Cost Driver di RS "X" Surabaya

\begin{tabular}{cllr}
\hline \multirow{2}{*}{ No } & \multirow{2}{*}{ Nama Facility Activity } & \multicolumn{1}{c}{ Cost Driver } & $\begin{array}{c}\text { Jumlah Cost Driver Seluruh } \\
\text { RS }\end{array}$ \\
\hline 1 & Pelayanan Rekam Medis & Jumlah kunjungan pasien & 13421 pasien \\
2 & Pelayanan IPS & Frekuensi Pemeliharaan & $128 \mathrm{kali}$ \\
3 & Pelayanan Laundry & Jumlah item Laundry & 81789 item \\
4 & Pelayanan Keamanan & Luas Lahan & $8756,67 \mathrm{~m}^{2}$ \\
5 & Pelayanan Cleaning Service & Luas Lahan & $8756,67 \mathrm{~m}^{2}$ \\
6 & Pelayanan Administrasi\& & Jumlah kunjungan pasien & 13421 pasien \\
\hline
\end{tabular}

waktu, penelitian termasuk ke dalam rancang bangun penelitian cross sectional.

Unit analisis penelitian ini adalah RS "X" Surabaya dengan menggunakan sumber informasi yang dipilih berdasarkan tujuan penelitian, yaitu:

1. Manajer keuangan;

2. Staf bagian keuangan dan akuntansi;

3. Supervisor unit rawat jalan;

4. Kepala instalasi unit rawat jalan;

5. Supervisor IPSRS;

6. Supervisor SIRS;

7. Supervisor sanitasi dan $\mathrm{HK}$;

8. Supervisor rekam medis;

\section{HASIL DAN PEMBAHASAN}

\section{Aktivitas Penunjang}

Klinik spesialis bedah saraf merupakan aslah satu klinik unggulan di RS " $X$ " Surabaya dan sebagai salah satu klinik di unit rawat jalan. Pada proses pelayanan kepada pasien, rumah sakit memiliki aktivitas penunjang (facility activity) yang menopang proses umum produksi. Berikut adalah hasil identifikasi aktivitas penunjang di RS "X" Surabaya: 


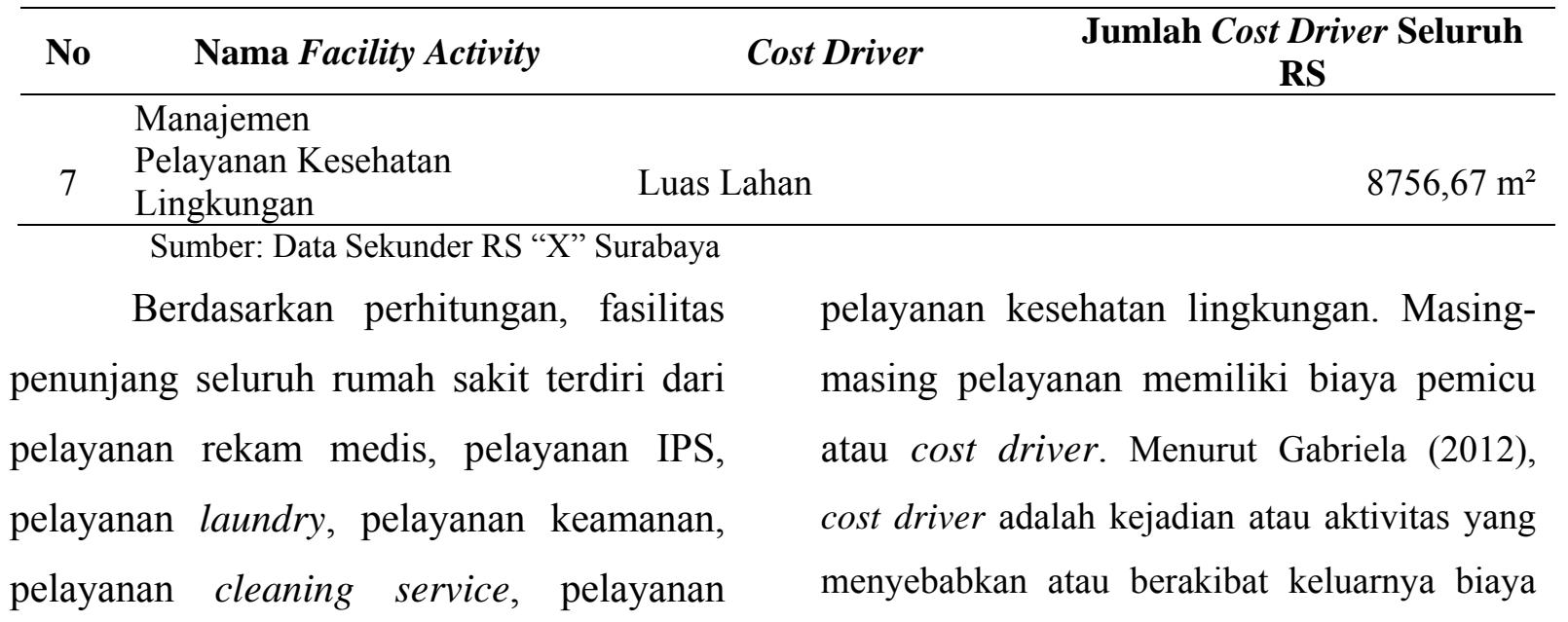
administrasi dan manajemen, serta

Tabel 3. Pembebanan Cost Driver ke Klinik Spesialis Bedah Saraf

\begin{tabular}{rlr}
\hline NO & Nama Facility Activity & Klinik Sp. Bedah Saraf (Rp) \\
\hline 1 & Pelayanan Rekam Medis & 57.192 .084 \\
2 & Pelayanan IPS & 15.658 .627 \\
3 & Pelayanan Laundry & 61.808 \\
4 & Pelayanan Keamanan & 1.176 .282 \\
5 & Pelayanan Cleaning Service & 3.209 .746 \\
6 & Pelayanan Admin \& Manajemen & 352.733 .635 \\
7 & Pelayanan Kesehatan Lingkungan & 1.568 .548 \\
\hline
\end{tabular}

Berdasarkan tabel 5.6 didapatkan biaya aktivitas penunjang di klinik spesialis bedah saraf yang paling tinggi adalah pada pelayanan administrasi dan manajemen senilai Rp. 352.733 .635 dan yang palingrendah adalah pelayanan laundry Tabel 4. Produk Pelayanan Klinik Spesialis Bedah Saraf

\begin{tabular}{clcc}
\hline No & \multicolumn{1}{c}{ Produk Pelayanan } & $\begin{array}{c}\text { Jumlah } \\
\text { Pelayanan } \\
\text { per tahun }\end{array}$ & $\begin{array}{c}\text { Waktu Pelayanan } \\
\text { (menit) }\end{array}$ \\
\hline 1 & Konsultasi dokter & 2457 & 30 \\
2 & Injeksi Keloid/Injeksi akupuntur besar $(>5 \mathrm{~cm})$ & 1 & 55 \\
3 & Injeksi Keloid/Injeksi akupuntur kecil $(\leq 5 \mathrm{~cm})$ & 1 & 55 \\
4 & Rawat luka tanpa angkat jahitan kecil $(1-5$ jahitan) & 1 & 25 \\
5 & Rawat luka tanpa angkat jahitan sedang $(6-15$ jahitan) & 1 & 30 \\
6 & Rawat luka tanpa angkat jahitan besar $(>15$ jahitan$)$ & 1 & 40 \\
7 & Rawat luka dan angkat jahitan kecil $(1-5$ jahitan) & 1 & 25 \\
8 & Rawat luka dan angkat jahitan sedang $(6-15$ jahitan) & 1 & 30 \\
9 & Rawat luka dan angkat jahitan besar $(>15$ jahitan) & 1 & 40 \\
\hline \multicolumn{2}{c}{ TOTAL } & 2465 & \\
\hline
\end{tabular}

senilai Rp. 61.808. Biaya penunjang selanjutnya akan dimasukkan ke setiap aktivitas produk pelayanan. Berikut adalah jenis produk pelayanan dan jumlah pasien tahun 2015 di klinik spesialis bedah saraf: 
Berdasarkan table 3, diketahui bahwa jumlah pasien terbanyak di klinik spesialis bedah saraf adalah produk pelayanan konsultasi dokter sebanyak 2457 pasien, sedangkan produk pelayanan lainnya hanya terdiri dari 1 pasien dan produk pelayanan yang memiliki waktu pelayanan terendah adalah produk Rawat luka tanpa angkat jahitan kecil (1-5 jahitan) dan Rawat luka dan angkat jahitan kecil (15 jahitan) dengan waktu pelayanan selama 25 menit.

\section{Biaya Tidak Langsung}

Biaya tidak langsung adalah biaya yang dibebankan pada sumber biaya yang mempunyai fungsi penunjang (aktivitas tak langsung) terhadap output (Pudjirahardjo et al. 1998). Biaya tidak langsung di unit rawat jalan RS " $X$ " didasarkan pada proporsi jumlah pasien di setiap klinik. Biaya tidak langsung di klinik spesialis bedah saraf sejumlah Rp. 90.642.680. Biaya tidak langsung terdiri dari penjumlahan antara biaya depersiasi gedung dan alat non medis, biaya biaya operasional, dan biaya pemeliharaan.

\section{Biaya Langsung}

Biaya langsung adalah biaya yang dibebankan pada sumber biaya yang mempunyai fungsi atau aktivitas langsung terhadap output (Pudjirahardjo et al. 1998). Biaya langsung terdiri dari penjumlahan biaya bahan atau BHP medis, biaya pegawai per tindakan, dan biaya alat medis yang digunakan. Berikut adalah hasil identifikasi biaya langsung di klinik spesialis bedah Surabaya:

Tabel 5 Biaya langsung Produk Pelayanan Klinik Spesialis Bedah Saraf

\begin{tabular}{rlccrr}
\hline No & \multicolumn{1}{c}{ Produk Pelayanan } & $\begin{array}{c}\text { Biaya } \\
\text { Bahan } \\
\text { (Rp) }\end{array}$ & $\begin{array}{c}\text { Biaya } \\
\text { Pegawai } \\
\text { (Rp) }\end{array}$ & $\begin{array}{c}\text { Biaya Alat } \\
\text { (Rp) }\end{array}$ & $\begin{array}{c}\text { Total Biaya } \\
\text { Langsung (Rp) }\end{array}$ \\
\hline 1 & $\begin{array}{l}\text { Konsultasi dokter } \\
\text { Injeksi Keloid/Injeksi } \\
\text { akupuntur besar }(>5 \mathrm{~cm})\end{array}$ & 32.794 & 141.074 & 353 & 84.363 \\
3 & $\begin{array}{l}\text { Injeksi Keloid/Injeksi } \\
\text { akupuntur kecil }(\leq 5 \mathrm{~cm})\end{array}$ & 31.860 & 141.074 & 353 & 250.786 \\
4 & $\begin{array}{l}\text { Rawat luka tanpa angkat } \\
\text { jahitan kecil (1-5 jahitan) }\end{array}$ & 39.413 & 64.124 & 161 & 103.698 \\
5 & $\begin{array}{l}\text { Rawat luka tanpa angkat } \\
\text { jahitan sedang (6-15 jahitan) }\end{array}$ & 47.818 & 76.949 & 193 & 124.960 \\
6 & $\begin{array}{l}\text { Rawat luka tanpa angkat } \\
\text { jahitan besar }>15 \text { jahitan) }\end{array}$ & 75.746 & 102.599 & 257 & 178.602 \\
7 & $\begin{array}{l}\text { Rawat luka dan angkat jahitan } \\
\text { kecil (1-5 jahitan) }\end{array}$ & 39.545 & 64.124 & 161 & 103.831 \\
8 & $\begin{array}{l}\text { Rawat luka dan angkat jahitan } \\
\text { sedang (6-15 jahitan) }\end{array}$ & 47.950 & 76.949 & 194 & 125.093 \\
9 & $\begin{array}{l}\text { Rawat luka dan angkat jahitan } \\
\text { besar (>15 jahitan) }\end{array}$ & 75.878 & 102.599 & 258 & 178.735 \\
\hline
\end{tabular}


Pada tabel 5 diketahui biaya langsung paling tinggi di klinik spesialis bedah saraf adalah produk Rawat luka dan angkat jahitan besar ( $>15$ jahitan) senilai Rp. 178.479,00. Produk pelayanan yang memiliki biaya langsung terendah adalah konsultasi dokter senilai Rp.84.171,00.

Biaya pegawai didapatkan dari pembagian antara total gaji pegawai dengan waktu pelayanan klinik selama satu tahun. Berikut adalah rincian gaji pegawai klink spesialis bedah saraf:

Tabel 6. Biaya Pegawai Medis Klinik Spesialis Bedah Saraf

\begin{tabular}{lr}
\hline $\begin{array}{c}\text { Nama Tenaga Kerja } \\
\text { Medis/Paramedis }\end{array}$ & \multicolumn{1}{c}{$\begin{array}{c}\text { Jumlah Gaji } \\
\text { Setahun (Rp) }\end{array}$} \\
\hline Dokter Spesialis & 625.354 .683 \\
Bedah Saraf & 14.863 .785 \\
Perawat & $\mathbf{6 4 0 . 2 1 8 . 4 6 8}$ \\
\hline \multicolumn{1}{c}{ Jumlah }
\end{tabular}

Waktu pelayanan selama satu tahun di klinik spesialis bedah orthopedi adalah 249.000 menit sehingga biaya per menitnya setelah jumlah gaji dibagi dengan total waktu pelayanan adalah Rp. 2.565,00.

\section{Unit Cost}

$\mathrm{ABC}$ merupakan suatu pendekatan kalkulasi biaya satuan yang memfokuskan pada aktivitas sebagai obyek biaya yang fundamental dan menggunakan biaya dari aktivitas sebagai dasar untuk mengalokasikan biaya ke obyek biaya yang lain seperti produk, jasa atau pelanggan (Horngren et al. 2000). Pada perhitungan biaya satuan (unit cost) penelitian ini didapatkan dari penjumlahan antara biaya langsung dengan biaya tidak langsung.

Tabel 7. Unit Cost Klinik Spesialis Bedah Saraf

\begin{tabular}{|c|c|c|c|c|}
\hline No & Produk Pelayanan & $\begin{array}{c}\text { Biaya } \\
\text { Langsung } \\
\text { (Rp) } \\
\end{array}$ & $\begin{array}{c}\text { Biaya Tidak } \\
\text { Langsung (Rp) }\end{array}$ & Unit Cost (Rp) \\
\hline 1 & Konsultasi dokter & 312.221 & 211.805 & 296.168 \\
\hline 2 & $\begin{array}{l}\text { Injeksi Keloid/Injeksi akupuntur } \\
\text { besar }(>5 \mathrm{~cm})\end{array}$ & 250.786 & 350.669 & 662.890 \\
\hline 3 & $\begin{array}{l}\text { Injeksi Keloid/Injeksi akupuntur } \\
\text { kecil }(\leq 5 \mathrm{~cm})\end{array}$ & 103.698 & 350.669 & 601.455 \\
\hline 4 & $\begin{array}{l}\text { Rawat luka tanpa angkat jahitan } \\
\text { kecil (1-5 jahitan) }\end{array}$ & 124.960 & 131.148 & 234.846 \\
\hline 5 & $\begin{array}{l}\text { Rawat luka tanpa angkat jahitan } \\
\text { sedang (6-15 jahitan) }\end{array}$ & 178.602 & 174.864 & 299.824 \\
\hline 6 & $\begin{array}{l}\text { Rawat luka tanpa angkat jahitan } \\
\text { besar ( }>15 \text { jahitan) }\end{array}$ & 103.831 & 262.295 & 440.898 \\
\hline 7 & $\begin{array}{l}\text { Rawat luka dan angkat jahitan kecil } \\
\text { (1-5 jahitan) }\end{array}$ & 125.093 & 131.148 & 234.978 \\
\hline 8 & $\begin{array}{l}\text { Rawat luka dan angkat jahitan } \\
\text { sedang (6-15 jahitan) }\end{array}$ & 178.735 & 174.864 & 299.956 \\
\hline 9 & $\begin{array}{l}\text { Rawat luka dan angkat jahitan besar } \\
(>15 \text { jahitan })\end{array}$ & 312.221 & 262.295 & 441.031 \\
\hline
\end{tabular}


Unit cost mencerminkan realitas berbagai variabilitas biaya yang terjadi berkaitan dengan pelayanan kesehatan yang diberikan di rumah sakit akan memberikan berbagai manfaat untuk keperluan: penetapan kebijakan tarif atau pricing policy, meningkatkan efisiensi dan cost effectiveness rumah sakit, dan penentuan besaran subsidi untuk jenis-jenis pelayanan kesehatan tertentu, serta penentuan rugi laba operasional rumah sakit, bahkan bisa digunakan sebagai patokan dasar dalam menentukan Rencana Bisnis Anggaran (RBA) (Subanegara, 2005). Kuchta \& Zabek (2011) mengatakan bahwa konsep dasar metode $\mathrm{ABC}$ terdapat pada sumber biaya langsung dan tidak langsung, facility activity yang dimiliki pelayanan kesehatan, aktivitas pelayanan, dan juga pemicu biaya.

Penentuan satuan biaya produk untuk metode tradisional dimasa lalu hanya pada satu cost driver, untuk mengatasi kelemahan system penentuan cost tradisional, maka diperlukan sistem akuntansi aktivitas. ABC System membebankan cost ke produk atau jasa berdasarkan konsumsi terhadap aktivitas. Sistem ini menggunakan dasar pemikiran bahwa produk atau jasa perusahan diperoleh melalui pelaksanaan aktivitas dan aktivitas tersebut membutuhkan cost (Mulyadi, 2003).

\section{Perbandingan Tarif dengan Unit Cost}

Tabel 8. Perbandingan Tarif dengan Unit Cost Klinik Spesialis Bedah Saraf

\begin{tabular}{|c|c|c|c|c|}
\hline No & Produk Pelayanan & $\begin{array}{l}\text { Unit Cost } \\
\text { (Rp) }\end{array}$ & $\begin{array}{l}\text { Tarif } 2016 \\
(\mathrm{Rp})\end{array}$ & Keterangan \\
\hline 1 & Konsultasi dokter & 296.168 & 450.000 & Rasional \\
\hline 2 & $\begin{array}{l}\text { Injeksi Keloid/Injeksi akupuntur } \\
\text { besar }(>5 \mathrm{~cm})\end{array}$ & 662.890 & 250.000 & Tidak Rasional \\
\hline 3 & $\begin{array}{l}\text { Injeksi Keloid/Injeksi akupuntur } \\
\text { kecil }(\leq 5 \mathrm{~cm})\end{array}$ & 601.455 & 150.000 & Tidak Rasional \\
\hline 4 & $\begin{array}{l}\text { Rawat luka tanpa angkat jahitan kecil } \\
\text { (1-5 jahitan) }\end{array}$ & 234.846 & 144.413 & Rasional BL \\
\hline 5 & $\begin{array}{l}\text { Rawat luka tanpa angkat jahitan } \\
\text { sedang (6-15 jahitan) }\end{array}$ & 299.824 & 187.818 & Rasional BL \\
\hline 6 & $\begin{array}{l}\text { Rawat luka tanpa angkat jahitan } \\
\text { besar ( }>15 \text { jahitan) }\end{array}$ & 440.898 & 275.746 & Rasional BL \\
\hline 7 & $\begin{array}{l}\text { Rawat luka dan angkat jahitan kecil } \\
\text { (1-5 jahitan) }\end{array}$ & 234.978 & 226.545 & Rasional BL \\
\hline 8 & $\begin{array}{l}\text { Rawat luka dan angkat jahitan } \\
\text { sedang (6-15 jahitan) }\end{array}$ & 299.956 & 297.950 & Rasional BL \\
\hline 9 & $\begin{array}{l}\text { Rawat luka dan angkat jahitan besar } \\
(>15 \text { jahitan })\end{array}$ & 441.031 & 475.878 & Rasional \\
\hline
\end{tabular}


Menurut Trisnantoro (2006), tarif adalah nilai suatu jasa layanan yang diterapkan dengan ukuran sejumlah uang berdasarkan pertimbangan bahwa dengan nilai uang tersebut sebuah rumah sakit bersedia memberikan jasa kepada pasien. Berdasarkan hasil perbandingan tarif dengan unit cost pada table 8 di klinik spesialis bedah saraf didapatkan bahwa dari total 9 produk pelayanan, terdapat 2 tarif yang rasional, 5 tarif rasional dengan biaya langsung, dan 2 tarif tidak rasional.

Tarif rumah sakit yang digunakan sebagai perbandingan adalah tarif RS " $X$ " Surabaya pada tahun 2016. Beberapa tarif produk pelayanan tidak termasuk bahan medis sedangkan unit cost sudah termasuk biaya bahan medis. Keterangan "Rasional" berarti tarif rumah sakit tahun 2016 berada di atas unit cost, "Rasional BL" berarti tarif hanya berada diatas biaya langsung, dan keterangan "Tidak Rasional" menunjukkan tarif rumah sakit berada dibawah biaya langsung maupun unit cost. Tarif dengan keterangan tidak rasional yang harus menjadi evaluasi bagi RS “X” Surabaya.

Menurut Arnalbodi dan Lapsley (2005), implementasi penetapan tarif yang didasarkan metode $\mathrm{ABC}$ memiliki beberapa faktor pengaruh, yaitu dukungan dari top management, corporate strategy dan sumber daya yang dimiliki, adanya tim champion untuk ABC, konsultan eksternal, ukuran tim dan heterogenisasinya, lingkungan yang kompetitif, serta pelatihan dan interaksi dalam sistem organisasi. proses implementasi biaya satuan dalam organisasi akan membawa pada peningkatan performance management yang harus didukung oleh teknologi dan proses tersebut akan melewati fase penurunan kemampuan pada saat awal penerapan hingga kemudian perlahan meningkat (the $\mathrm{ABC}$ hype cycle) (Turney, 2008).

Keakuratan pengalokasian setiap biaya tergantung pada tingkat korelasi antara konsumsi aktivitas dan konsumsi cost driver. Jadi, secara keseluruhan, tarif produk pelayanan di klinik spesialis bedah saraf RS "X" Surabaya cenderung lebih murah dibandingkan unit cost yang telah dihitung dapat disebabkan oleh:

1. Output pelayanan yang kecil, fungsi output adalah sebagai pembagi biaya tidak langsung pada aktivitas primer. Semakin besar output atau jumlah pasien, maka akan semakin kecil biaya tidak langsung setiap produk dan semakin kecil unit cost produk tersebut;

2. Waktu aktivitas yang lama, semakin lama waktu pelayanan, maka akan semakin besar pula biaya tenaga kerja medis dan biaya alat medis yang dibebankan;

3. Biaya tidak langsung besar, seperti biaya gedung, peralatan non medis, 
hingga pemeliharaannya yang cukup mahal tidak sebanding dengan hasil penggunaannya;

4. Jumlah cost driver yang besar, semakin besar cost driver baik pada facility activity maupun unit activity akan membuat biaya yang dibebankan semakin besar.

Menurut Garrison dan Norren (2000:42), metode ABC yang tidak didukung dengan data yang tidak akurat dapat menyesatkan dan menghasilkan kesalahan yang berdampak pada pengambilan keputusan strategi yang kurang optimal. Hal tersebut menjadi kelemahan perhitungan biaya satuan pada penelitian ini karena terdapat data khususnya pada data inventaris aset yang kurang lengkap sehingga memungkinkan ketidakakuratan hasil perhitungan.

Menurut Turney dalam Carter (2009:548), secara umum terdapat empat cara untuk mengelola aktivitas dalam metode ABC guna mencapai perbaikan dalam suatu proses produk pelayanan, yaitu:

1. Pengurangan aktivitas

Mengurangi aktivitas berarti mengurangi waktu atau usaha yang diperlukan untuk melakukan aktivitas tersebut. Contohnya adalah aktivitas konsultasi dokter dari 30 menit waktu konsultasi dikurangi menjadi 15 menit.

2. Eliminasi aktivitas
Mengeliminasi aktivitas berarti menghilangkan aktivitas tersebut seluruhnya. Contohnya adalah menghilangkan aktivitas entry tindakan dan input BHP karena telah memakai unit cost sehingga BHP tidak terpisah dari tarif yang ada dalam sistem.

3. Seleksi aktivitas

Melakukan seleksi berarti memilih alternatif yang berbiaya rendah dari sekelompok alternatif desain. Contohnya adalah mengganti tindakan medis yang dirasa terlalu memakai jenis BHP medis yang mahal diganti dengan BHP dengan nilai yang lebih rendah.

RS "X” Surabaya sebagai rumah sakit swasta yang berada pada fase berkembang dapat menggunakan metode ABC pada seluruh produk pelayanan dengan mengelola aktivitas di setiap produk untuk mencegah timbulnya hasil tarif tidak rasional dan fokus mengevaluasi tarif untuk dasar perencanaan target profit secara tepat sehingga hasil tarif sesuai dengan kondisi di organisasi dan masyarakat. Pada fase ini RS "X" Surabaya tetap mendapatkan pendapatan dari hasil subsidi silang pelayanan operasi dan pelayanan bedah saraf di klinik spesialis bedah saraf yang memiliki tingkat utilitas paling tinggi sehingga dapat membantu menyokong kebutuhan biaya bagi proses pelayanan lainnya. 
Metode ABC memberikan keuntungan selain dapat mengevaluasi tarif juga dapat melakukan standarisasi pelayanan. Rumah sakit dapat menjadikan standarisasi pelayanan sebagai alat monitoring rumah sakit dalam setiap proses pelayanan sehingga akan berdampak pada efisiensi aktivitas dan biaya yang dikeluarkan. Adanya pedoman pratik pelayanan di rumah sakit belum cukup untuk memperkuat batasan pelaksanaan tindakan medis yang dilakukan dokter maupun perawat, oleh karena itu rumah sakit dianjurkan memiliki clinical pathway.

\section{SIMPULAN}

Facility activity yang menunjang pelayanan di unit produksi adalah aktivitas pelayanan rekam medis, pelayanan IPS, pelayanan laundry, pelayanan keamanan, pelayanan cleaning service, pelayanan administrasi dan manajemen, dan pelayanan kesehatan lingkungan.

Pembebanan biaya tidak langsung facility activity dilakukan pada unit radiologi, rawat jalan, dan rawat inap dilakukan dengan mangalikan cost driver dengan rate per cost driver facility activity.

Klinik spesialis bedah saraf memiliki 9 produk pelayanan

kemudian produk tersebut di klasifikasikan dalam aktivitas primer dan sekunder serta dihitung waktu aktivitas sebagai dasar penghitungan biaya selanjutnya.

Biaya langsung setiap produk pelayanan diperoleh melalui penjumlahan biaya BHP medis, biaya tenaga medis dan biaya alat medis.

Biaya tidak langsung setiap produk pelayanan diperoleh dengan membebankan aktivitas sekunder pada aktivitas primer dan membagi total biaya tidak langsung per tahun dengan output pelayanan.

Hasil penghitungan unit cost dengan metode ABC klinik spesialis bedah saraf RS "X" Surabaya berasal dari penjumlahan biaya langsung dan biaya tidak langsung setiap produk pelayanan Tarif produk pelayanan RS " $X$ " Surabaya setelah dibandingkan dengan unit cost yang dihitung dengan metode $\mathrm{ABC}$ memiliki hasil2 tarif pelayanan yang rasional, 5 tarif rasional biaya langsung, dan 2 tarif lainnya adalah tarif tidak rasional yang disebabkan oleh output pelayanan kecil, waktu aktivitas besar, biaya tidak langsung besar, dan jumlah cost driver yang besar.

\section{SARAN}

Unit cost produk pelayanan yang dihitung dengan metode $\mathrm{ABC}$ hendaknya dapat dijadikan 
pertimbangan bagi RS " $X$ " Surabaya dalam proses evaluasi dan penentuan tarif selanjutnya oleh Tim Tarif dengan menggunakan strategi cost based pricing sebagai upaya penerapan activity based management;

RS "X" Surabaya hendaknya melakukan efisiensi biaya pada bagian administrasi dan manajemen dengan menekan kegiatan yang tidak berhubungan langsung dengan pasien di setiap unit kerja, misalnya pada biaya umum (listrik, air, telepon/internet) dan efisiensi pada bagian IPSRS dengan menekan biaya pemeliharaan melalui peningkatan proses maintenance alat baik medis maupun non medis dan juga dapat mencantumkan prosedur utilisasi alat untuk memimalisir kerusakan akibat faktor human error;

Adanya tarif yang tidak rasional hendaknya dijadikan sebagai upaya meningkatkan utilitas produk pelayanan di RS "X" Surabaya;

RS "X" Surabaya hendaknya melakukan pengarsipan data inventaris aset secara digital dan tersistem oleh bagian SIRS untuk memudahkan pendataan baik dalam proses perhitungan unit cost maupun keperluan lain;

Satuan Medis Fungsional RS "X" Surabaya hendaknya melakukan standarisasi pelayanan disetiap unit produksi dan membuat clinical pathway untuk mengetahui batasan dan prosedur setiap tindakan medis yang dilakukan oleh tenaga medis kepada pasien;

Perlu dilakukan penelitian tentang utilitas produk pelayanan di RS "X" Surabaya untuk meningkatkan jumlah produksi rumah sakit sehingga dapat meminimalisir kerugian;

RS "X” Surabaya dapat mengelola aktivitas produk di setiap unit guna perbaikan proses pelayanan dengan cara pengurangan aktivitas, eliminasi aktivitas, seleksi aktivitas, atau berbagi aktivitas sebagai upaya efisiensi biaya dan standarisasi pelayanan.

\section{DAFTAR PUSTAKA}

Arnalbodi, Michela \& Irvine Lapsley. 2005. Activity Based Costing In Healthcare :A UK Case Study. Research In Healthcare Financial Management Vol 10, No, 1, page: 6175.

Carter, WK. 2009. Akuntannsi Biaya Cost Accounting. Salemba empat. Jakarta.

Gabriela, 2012. Penerapan Activity Based Costing Pada Tarif Jasa Rawat Inap Rumah Sakit Umum Daerah di Makassar. Makasar: Universitas Hasanuddin.

Garrison, Ray dan Norren, Eric W. 2000. Akuntansi Manajerial. Diterjemahkan oleh Totok Bidisantoso. Buku 1. Jakarta: Salemba Empat.

Horngren, dkk. 2008. Akuntansi Biaya. Jakarta : Penerbit Erlangga. 
Keputusan Menteri Kesehatan Republik Indonesia Nomor 560/MENKES/SK/IV/2003 Tentang Pola Tarif Perjan Rumah Sakit.

Kuchta, Dorota \& Zabek, Sabina, 2011. Activity-based costing for health care instutions. Wroclauw University of technology, Poland.

Mininjaya, AAG. 2004. Manajemen Kesehatan, ECG, Bali.

Mulyadi, 2003. Activity Based Cost System Sistem Informasi Biaya untuk Pengurangan Biaya . Yogyakarta : UPPAMP YKPN.

Pudjirahardjo W.J., Supriyanto S., Nyoman A.D., Thinni N.R. dan Djazully C.,1998. Analisis Biaya Satuan dan Penyesuaian Tarif Pelayanan Rumah Sakit. Surabaya: Program Studi AKK FKM UNAIR.

Subanegara, HP. 2005. Modul Unit Cost Analisis Rumah Sakit. Hospital Management Consultant.

Trisnantoro, 2006. Manajemen Rumah Sakit. Yogyakarta: Gajah Mada UniversityPress:146-163.

Turney, Peter B.B. 2008. Activity-Based Costing, An Emerging Foundation For Performance Management. Strategic Analysis Report: Gartner Research 2003.

Undang-Undang No. 44 Tahun 2009 Tentang Rumah Sakit. 